\title{
COVID-19 e a promoção da saúde em tempos de pandemia
}

\author{
COVID-19 and health promotion in pandemic times
}

\author{
COVID-19 y promoción de la salud em tiempos pandémicos
}

José Roberto de Souza-Junior ${ }^{1}$, Roberta Cristina Ribeiro $\mathrm{Cruz}^{2}$, Vinícius Cardoso-Brito ${ }^{3}$, Estela Larissa Silva dos Santos ${ }^{3}$, Mellanie Fontes-Dutra ${ }^{4}$, Izabella Muraro de Freitas ${ }^{4}$, Amanda Garcia Pereira $^{2}$, Guilherme Barbosa da Costa², Silvio de Almeida-Junior ${ }^{2}$, Fabíola Pansani Maniglia ${ }^{2 *}$.

\section{RESUMO}

Objetivo: Analisar e descrever através de uma revisão sobre quais são os possíveis impactos, metodologias de prevenção e soluções dentro dos parâmetros pandêmicos da Covid-19, de uma maneira clara e destinada ao público, com intuito de promover conscientização e ampliar o conhecimento. Revisão bibliográfica: A pesquisa foi realizada de forma exploratória e qualitativa no contexto dos acontecimentos atuais, e nas opiniões científicas encontradas na atualidade sobre dados epidemiológicos do COVID-19. Demonstrou-se o aumento nocivo da doença de forma descontrolada e seus reflexos recorrentes devido à falta efetiva de uma incursão educacional, legislativa e nutricional. O despreparo em enfrentar e prevenir as mazelas da sociedade ocasionadas pela fácil transmissão e propagação de doenças infecto-agressivas, e sua abrangência nos vários setores da sociedade brasileira. Notou-se também que manobras emergenciais esbarraram nos entraves burocráticos. Considerações finais: Após a consecução da pesquisa houve um vislumbre ainda das falhas governamentais e da própria população frente as suas possíveis ações para evitar e combater casos excepcionais de perigo iminente.

Palavras-chave: Brasil, Coronavírus, Cuidados, Epidemiologia, Síndrome respiratória aguda grave.

\section{ABSTRACT}

Objective: To analyze and describe what are the possible impacts prevention methodologies and solutions within the Covid-19 pandemic parameters, in a clear way and aimed at the public, in order to promote awareness and expand knowledge. Literature review: The research was carried out in an exploratory and qualitative way in the context of current events, and in the scientific opinions found today on epidemiological data from COVID-19. The unhealthy increase of the disease and its recurent reflexes have been demonstrated due to the lack of an effective educational, legislative, and nutritional incursion. The unpreparedness to face and prevent the ills of society caused by the easy transmission and spread of infectious-aggressive diseases, and their scope in the various sectors of Brazilian society. It was also noted that emergency maneuvers ran into bureaucratic obstacles. Final considerations: After completing the research, there was still a glimpse of governmental failures and of in view of their possible actions to prevent and combat exceptional cases of imminent danger.

Key words: Brazil, Coronavirus, Care, Epidemiology, Severe acute respiratory syndrome.

\section{RESUMEN}

Objetivo: Analizar y describir cuáles son los posibles impactos, metodologías de prevención y soluciones dentro de los parámetros de la pandemia Covid-19, de manera clara y dirigida al público, para promover la conciencia y expandir el conocimiento. Revisión bibliográfica: La investigación se llevó a cabo de forma exploratoria y cualitativa en el contexto de los acontecimientos actuales y en las opiniones científicas que se encuentran actualmente en los datos epidemiológicos de COVID-19. El aumento poco saludable de la enfermedad y sus reflejos recurrentes se han demostrado debido a la falta de una incursión educativa, legislativa y nutricional efectiva. La falta de preparación para enfrentar y prevenir los males de la sociedad

\footnotetext{
1Universidade Estadual de Minas Gerais (UEMG), Passos - MG. *E-mail: fabiola.maniglia@unifran.edu.br ${ }^{2}$ Universidade de Franca (UNIFRAN), Franca - SP.

3 Universidade Federal da Bahia (UFBA), Salvador - BA.

${ }^{4}$ Universidade Federal do Rio Grande do Sul (UFRGS), Porto Alegre - RS.
}

SUBMETIDO EM: 5/2020

PUBLICADO EM: 8/2020 
causados por la fácil transmisión y propagación de enfermedades infecciosas agresivas y su alcance en los diversos sectores de la sociedad brasileña. También se observó que las maniobras de emergencia se toparon con obstáculos burocráticos. Consideraciones finales: Después de completar la investigación, todavía se vislumbraban fallas gubernamentales y de la población misma en vista de sus posibles acciones para prevenir y combatir casos excepcionales de peligro inminente.

Palabras clave: Brasil, Coronavirus, Atención, Epidemiologia, Síndrome respiratorio agudo severo.

\section{INTRODUÇÃO}

É público e notório que o Brasil, tal qual inúmeros países do globo, viveu no início do ano de 2020 uma crise pandêmica, ocasionada por um novo coronavírus (HUANG C, et al., 2020; GUO YR, et al., 2020). Atualmente, existe uma grande família de coronavírus ( $\mathrm{CoV}$ - família coronoviridae) que podem afetar desde mamíferos, até mesmo espécies aviarias (DECARO N, et al., 2013). Em humanos, o vírus responsável pela proliferação da atual pandemia da doença denominada Covid-19, é o SARS-CoV-2, vírus de fita de RNA simples positivo e envelopado, com seu primeiro relato em dezembro de 2019 na China (SOHRABI C, et al., 2020).

No atual cenário, nos deparamos com números crescentes que superam três milhões de casos confirmados e duzentas mil mortes em todo o mundo, assim como o despreparo sanitário e a reduzida capacidade em lidar com pandemias de em muitas nações, refletindo em uma desestabilização em todas as áreas da população, principalmente na saúde, economia e no direito (KAMEL BOULOS MN e GERAGHTY EM, 2020).

Muitos países estão utilizando de estratégias para minimizar os casos tais como demanda por leitos hospitalares, proteção de indivíduos mais vulneráveis, incluindo idosos e morbidades, além da promoção de saúde a todos, incluindo educação em saúde como lavagem de mãos, distanciamento social, cancelamentos de serviços públicos de larga escala entre outros, podendo citar países como Argentina e Nova Zelândia (BELINGHERI M, et al., 2020, JÚNIOR S de A, et al., 2020a).

Apesar do número de casos, muitas incertezas quanto às características epidemiológicas, soroepidemiológicas, clínicas e virológicas ainda permanecem (ROTHAN HA e BYRAREDDY SN, 2020). Devido a esses fatores, quanto mais informação e aplicação de metodologias de prevenção à população tiver, maiores as chances de se evitar e reduzir o crescimento da curva de infecção e mortes causadas pelo novo vírus. Frente a esta crise $o$ artigo se faz necessário para compreender as ações da promoção de saúde na atual situação pandêmica de uma maneira de fácil entendimento, com informações que possam atualizar a população e auxiliar durante o período que esta situação perdurar (JÚNIOR S de A, et al., 2020a).

O presente artigo tem como objetivo analisar e descrever através de uma revisão sobre quais são os possíveis impactos, metodologias de prevenção e soluções dentro dos parâmetros pandêmicos da Covid-19, de uma maneira clara e destinada ao público, com intuito de promover conscientização e ampliar o conhecimento.

\section{REVISÃO BIBLIOGRÁFICA}

Epidemias são classificadas como uma doença infecciosa, transmissível de uma região para outra, já as pandemias se diferem devido a sua maior proporção, podendo se espalhar por vários continentes, ou se estabelecer em todo o globo. Exemplos de pandemias recentes que podemos relatar são doenças como a gripe aviária em 2005 e a gripe suína em 2009. Elas se diferem de pandemias que ocorreram em épocas anteriores, devido principalmente à globalização e a facilidade de deslocamento populacional entre as regiões (TANNER WD, et al., 2015, REWAR S, et al., 2015, FRENK J e GÓMEZ-DANTÉS O, 2007).

Uma vez decretado o estado de pandemia, torna-se provável a restrição das liberdades fundamentais, com controle de viagens, fronteiras mais rígidas e interdições no cotidiano das pessoas (VENTURA D, 2009). Alguns autores e figuras públicas, por vezes assimilam este estado a um "estado de guerra", no qual ações podem ser impostas com finalidade de controle de doentes e mortes (SILVA JB e MUNIZ AMV, 2020). 
A Covid-19 teve seus primeiros relatos no dia 31 de dezembro de 2019 na cidade de Wuhan na China. Um mês depois o vírus já havia se espalhado rapidamente para inúmeros países, o que fez com que a Organização Mundial da Saúde declarasse uma Emergência de Saúde Pública de Interesse Internacional, com alto risco para países com sistema de saúde vulnerável (SOHRABI C, et al., 2020).

O período de incubação do vírus tem variação de 1 a 14 dias, com média de 5 a 6 dias para aparecimento dos sintomas como tosse seca, dispneia, febre, fadiga e dificuldade respiratória (HUANG C, et al., 2020, JÚNIOR $S$ de $A$, et al. 2020), e com menor frequência podemos encontrar quadros de diarreia, náuseas (HORMATI A, et al., 2020; SOHRABI C, et al., 2020), perda do olfato e paladar (XYDAKIS MS, et al., 2020) dores de cabeça, edema de tonsilas palatinas e excesso de secreção mucoide (ROTHAN HA e BYRAREDDY SN, 2020). Pacientes que possuam alguma doença prévia, assim como os mais idosos, normalmente estão associados aos que podem necessitar de terapia intensiva, contudo, isso não exclui os jovens ou pessoas sem enfermidades anteriores, dos cuidados intensivos (GUO YR, et al., 2020).

Os pacientes assintomáticos são aqueles que estão com o vírus em seu organismo, mas não apresentam sintomas da doença, o que acarreta em um desafio no controle, pois assim como as pessoas com sintomatologias, eles podem transmitir o vírus por meio do toque, gotículas de saliva, espirro, tosse, catarro e/ou pela contaminação de objetos ou superfícies (RAHIMI F e TALEBI BEZMIN ABADI A, 2020).

\section{A epidemiologia da pandemia de Covid-19}

As curvas epidêmicas refletem o que pode ser um padrão de surto misto, com casos iniciais sugestivos de uma fonte comum contínua, transbordamento potencialmente zoonótico no Mercado Atacadista de Frutos do Mar de Huanan e casos posteriores sugestivos de uma fonte propagada quando o vírus começou a ser transmitido de pessoa para pessoa (GUO YR, et al., 2020).

Até a data de 30 de junho, foram 11.483 .400 casos confirmados pelo mundo com total de 535.027 mortes. No Brasil, foram relatadas 64.900 mortes pelo COVID-19 com incidência de 1.604 .585 casos e letalidade de $4 \%$, acreditando que este número esteja subnotificado devido à demora na realização e liberação de exames moleculares (OPAS, 2020).

A transmissão do vírus, iniciado na China tem provável infecção horizontal e através de objetos compartilhados contaminados. Dessa forma, o vírus foi capaz de disseminar rapidamente dentro de hospitais e a propagação para a população se deu devido ao contágio direto. Devido à econômica e ao turismo, muitos dos navios e aviões saíam com as pessoas contaminadas, podendo apresentar sintomas ou não, levando 0 vírus a circular por todos os continentes (ROTHAN HA e BYRAREDDY SN, 2020).

\section{Planos diante da pandemia}

Em 30 de janeiro de 2020, a Organização Mundial da Saúde (OMS) declarou que o surto do novo coronavírus constitui uma Emergência de Saúde Pública de Importância Internacional, sendo este o mais alto nível de alerta da OMS, conforme previsto no Regulamento Sanitário Internacional, o qual orienta e busca a redução da propagação do vírus (ROTHAN HA e BYRAREDDY SN, 2020).

No Brasil, o Ministério da Saúde vem anunciando diferentes medidas para intensificar a vigilância, o diagnóstico e o tratamento do SARS-CoV-2, para também minimizar as mortes e o impacto econômico da propagação viral. Uma das medidas apresentadas foi a publicação do Plano de Contingência Nacional para Infecção Humana pelo novo Coronavírus (COVID-19) (JÚNIOR S de A, et al., 2020a).

As principais abordagens de saúde pública são a busca de pacientes positivos e rastreamento de seus contactantes e utilização do distanciamento social, também chamado pelos brasileiros de "quarentena" para preservar a saúde coletiva com a interrupção de aglomerações. Investimentos também vêm sendo realizados com instalações para diagnóstico e aconselhamentos de maneira remota, juntamente com tratamento especializado (ANDERSON RM, et al., 2020).

Os propósitos mais evidentes do distanciamento social estão voltados para reduzir a velocidade de transmissão, proteger a população de risco e especialmente ganhar tempo para a obtenção de mais leitos hospitalares (ANDERSON RN, et al., 2020). Contudo, muitas pessoas ainda não entendem que as ações não 
estão voltadas para "acabar" com o pico da enfermidade, pois uma vez que a doença vem acometendo a população, ele continuará a existir, seja ele baixo ou alto. As ações estão voltadas sim principalmente para termos um pico baixo e um prolongamento do tempo de aparecimento deste pico, para que tenhamos condições, físicas, estruturais, financeiras, sanitárias e bases cientificas para que menos mortes ocorram (GUO YR, et al., 2020).

Além dos propósitos mais evidentes da quarentena, decidir pelo isolamento previamente também pode trazer benefícios econômicos para o país. Países que adotaram a quarentena de forma mais prematura, conseguiram diminuir a duração do isolamento e apresentam uma recuperação mais rápida na economia, sendo assim, a adoção da quarentena no início da pandemia brasileira, pode significar uma vantagem econômica no final do surto (PARMET WE e SINHA MS, 2020).

Muitos economistas já fazem previsão de uma recessão mundial inevitável, e governos de todo o mundo estão aprovando pacotes de investimento dedicando-se para escapar do pior. Pode-se dizer que a crise econômica e a pandemia possuem um ponto semelhante, ambas se alastram em um ritmo frenético (PARMET WE e SINHA MS, 2020, LAUER AS, et al., 2020).

De igual forma, no Brasil não será diferente, caso não se tome medidas legislativas extremas. Nos últimos dias tem se notado ações para tentar conter o desastre econômico, como Projetos de Lei que visam, restringir o corte de energia elétrica, água e esgoto e suspensão do pagamento de aluguéis para manter as condições básicas da população (CRODA JHR e GARCIA LP, 2020). Porém, para os trabalhadores informais que estão em isolamento voluntário, sem auferir ganhos para o próprio sustento e de sua família, as medidas de auxílio financeiro devem ser urgentes e diretas, não apenas projetos de lei que auxiliam no pagamento de taxas e tributos, eles, mais do que qualquer parcela da população, necessitam de apoio financeiro para compra de bens básicos durante este período (GARCIA LP e DUARTE E, 2020).

\section{Preservação do estado de saúde populacional}

Para que a prevenção da propagação da Covid-19 tenha sucesso é necessária à conscientização de toda a população para que algumas ações simples sejam colocadas em prática, como o isolamento social e/ou quarentena para pessoas infectadas e o isolamento social voluntário para as pessoas não infectadas. Contudo, para ambos, o importante é frisar a higienização correta, principalmente com a lavagem das mãos com água e sabão ou quando não possível, a utilização de álcool em gel; limpeza de superfícies com álcool $70 \%$, educação e higiene respiratória cobrindo o nariz e a boca com o antebraço ao tossir ou espirrar, evitar aglomerações, evitar colocar as mãos na boca, olhos e nariz, manter a casa limpa e arejada, não compartilhar objetos com pessoas suspeitas ou confirmadas com coronavírus, são ações extremamente importantes neste período (JÚNIOR S de A, et al., 2020a).

Outras formas de prevenção incluem a limpeza de objetos como roupas, calçados, equipamentos de uso compartilhado como controle remoto, filtro de água, maçanetas, teclados e mouse de computadores (GARCIA LP e DUARTE E, 2020). Atualmente novas afirmações realizadas pelo diretor geral da OMS, apesar da relutância, aconselham a utilização de máscaras em comunidades onde outras medidas, como limpar as mãos e o distanciamento físico, são mais difíceis de serem alcançadas (MA Q, et al., 2020). A fim de se evitar também a escassez de mascaras "N95" para pessoas que estão diante de um maior risco de infecção, como os profissionais de saúde, pacientes e seus acompanhantes, (BELINGHERI M, et al., 2020, FENG S, et al., 2020) ações como endossar o uso de máscaras de panos vem sendo realizadas em inúmeros países, como ferramenta de biossegurança (JÚNIOR S de A, et al., 2020b).

Em meio a essa crise são também de extrema importância os cuidados com o estado mental das pessoas. Por mais eficiente que o isolamento social possa ser para a interrupção ou prevenção da transmissão do vírus, ele pode ocasionar danos emocionais como por exemplo, paranoias, depressão, histeria, pânico, crise de ansiedade, dentre outras, sendo fundamental o apoio psicológico e psiquiátrico por meio de profissionais habilitados para que não se tenha uma população com danos emocionais futuros (HO, CS, et al., 2020). Instituições médicas e universidades também estão destinando plataformas online para fornecer serviços de aconselhamento psicológico para suprir a necessidade crescente da população por este setor (ANDERSON RM, et al., 2020). 


\section{Nutrição e dietética}

Uma boa alimentação se enquadra como fator primordial na prevenção e tratamento da Covid-19 e está vinculada à melhoria da saúde física e mental de crianças, jovens, adultos e idosos, assim como fortalecimento do sistema imunológico (BUTLER MJ e BARRIENTOS RM, 2020). A dieta equilibrada com a constituição de todos os macros e micronutriente tua diretamente na prevenção de desnutrições, doenças crônicas não transmissíveis, como o diabetes, doenças cardiovasculares, câncer e doenças virais, além de potencializar o estado imunológico do paciente (KALANTAR-ZADEH K e MOORE LW, 2020).

É de extrema importância manter ou resgatar o hábito do consumo de alimentos in natura, como frutas, verduras, legumes e grãos integrais, além de proteínas de boa qualidade, temperos naturais, especiarias e principalmente a ingestão constante e suficiente de água (KALANTAR-ZADEH K e MOORE LW, 2020). Alimentos como o inhame, gengibre e o açafrão são considerados imunoestimulantes, e podem ser consumidos em forma de chás, sucos ou na preparação de refeições (CHANG JS, et al., 2013).

O cuidado com a higienização dos alimentos não deve ser esquecido, desde a aquisição, passando pelo preparo e o consumo deles. Deve-se sempre lavar as mãos, as embalagens e evitar falar, tossir e espirrar ao cozinhar. Além disso, devem-se armazenar os alimentos perecíveis adequadamente na geladeira e não consumir ovos e carnes cruas, higienizar as frutas, legumes e verduras em água corrente e colocá-las de molho em solução de hipoclorito ou água sanitária (BUTLER MJ e BARRIENTOS RM, 2020).

\section{Economia}

Outra situação que pode interferir na saúde da população, são as influências do estado de pandemia na economia regional e global, caracterizada por altas taxas de desempregos e lojas com redução de funcionário ou fechamento de portas, além das importações que também são afetadas, principalmente devido à China, foco do início da pandemia, ser atualmente uma das maiores fabricantes do mundo e importadora de petróleo. De certa forma, uma das soluções viáveis no presente momento não é somente o isolamento social ou quarentena, mas sim parcerias com entidades e empresas privadas com o escopo de empoderar e fortalecer novas produções hospitalares e insumos destinados ao tratamento médico dos contaminados pelo novo coronavírus de forma humanizada (SOHRABI C, et al., 2020). Embora ainda seja cedo para diagnosticar os danos econômicos advindos da pandemia pelo coronavírus, pode-se dizer com base nas fontes históricas que impérios e países foram balançados em suas estruturas econômicas em cenários de viés pandêmico (MARANHÃO RA e SENHORAS EM, 2020).

\section{Restrições}

Sohrabi C, et al. (2020) declaram que a resposta internacional ao Covid-19 foi mais transparente e eficiente quando comparada ao surto de SARS em 2002, mas ele elenca também tópicos a serem melhorados, como: atrasos na restrição de viagem, na imposição da quarentena e no anúncio de emergência, na informação pública e no desenvolvimento da pesquisa, para que se possa enfrentar de maneira mais eficiente as próximas enfermidades de risco mundial.

Wu J e Mcgoogan JM (2020) ressaltam que as restrições e as respostas ao atual surto servem para que a ciência tenha tempo para estabelecer e avançar, porém, a falta de estrutura prévia faz com que isso seja mais difícil. Apesar do pouco investimento na ciência e pesquisa (MARTINS V, 2019), avanços no isolamento do vírus, tratamento, e tentativas para frear o contágio têm sido notificados diariamente (BADEN LR e RUBIN EJ, 2020; TANG N, et al., 2020; WU J e McGOOGAN JM, 2020).

\section{Promoção da Saúde e Medicina Integrativas}

Em atenção à saúde da população, são propostas terapêuticas integrativas associadas aos tratamentos clínicos na intenção de auxiliar e melhorar a qualidade de vida da população durante a pandemia pelo COVID19 (LUO H, et al., 2020). Uma opção e que vem ganhando cada vez mais espaços em clínicas e consultórios é o conceito de práticas integrativas e complementares, termo descrito em debates de promoção da saúde devido a ser a junção de medicina tradicional com intervenções alternativas para atividade coadjuvante como forma de sinergismo e potencialização do tratamento prescrito (GUIMARÃES MB, et al., 2020). 
No Brasil a abundância de plantas medicinais, decorrente da diversidade vegetal, bem como o baixo custo, dá destaque à fitoterapia. Cada vez mais os programas de saúde pública vêm adotando essa técnica, visando seus efeitos benéficos em diversas patologias e também suas ações estimulantes para manutenção do sistema imunológico (BARROS LCN, et al., 2020).

Já a ozônioterapia é a terapia de maior impacto dentre as técnicas integrativas devido ao seu potencial. Sua eficiente ação em processos cicatriciais em lesões extensas, infecções fúngicas, bactérias e virais além de ser um potente oxidante em diversos casos, faz com que esta terapia seja cada vez mais estudada. Autores descrevem as ações citadas acima, bem como a ação do ozônio como gatilho na potencialização do sistema imunológico e no combate de diversos patógenos (WOLLHEIM C, et al., 2020; HERNÁNDEZ A, et al., 2020).

As utilizações de práticas milenares chinesas, entre elas a auriculoterapia e acupuntura sistêmica se mostraram efetivas na prevenção de várias doenças respiratórias durante toda a história, sendo indicada na China como medicina complementar na prevenção e tratamento adjunto ( $L U O \mathrm{H}$, et al., 2020), além do alívio de tensões e ansiedades devido ao confinamento e estresse vivido durante a quarentena (RUELA LO, et al., 2018).

\section{CONSIDERAÇÕES FINAIS}

A pandemia do Covid-19 demonstrou, na prática, que mesmo com o avanço tecnológico, a humanidade continua frágil diante do desconhecido. Contudo, com o mundo mais conectado do que nunca, ações coletivas são cada vez mais visualizadas. Novas pandemias são de certa forma esperadas, mas assim como esse novo coronavírus, não sabemos se será acarretada por vírus, bactéria ou protozoário. De todo modo, para que possamos reduzir os impactos causados por elas são imprescindíveis os investimentos na ciência, na saúde profilática e vigilância. Além disso, as estratégias interdisciplinares de promoção da saúde devem ser estimuladas para que a população se torne cada vez mais consciente, empoderada e agente ativa desse processo.

\section{AGRADECIMENTOS E FINANCIAMENTO}

O presente trabalho foi realizado com apoio da Coordenação de Aperfeiçoamento de Pessoal de Nível Superior - Brasil (CAPES) - Código de Financiamento 001, e conta com apoio financeiro do Conselho Nacional de Desenvolvimento Científico e Tecnológico (CNPq).

\section{REFERÊNCIAS}

1. ANDERSON RM, et al. How Will Country-Based Mitigation Measures Influence the Course of the COVID-19 Epidemic? The Lancet, 2002; 395(10228), 931-934.

2. BADEN LR, RUBIN EJ. Covid-19 - The Search for Effective Therapy. New England Journal of Medicine, 2020; 382:1851-1852

3. BARROS LCN, et al. Práticas Integradoras y Complementarias en la Atención Primaria de Salud: percepciones de los gestores de serviços. Escola Anna Nery, 2020; 24(2).

4. BELINGHERI M, et al. COVID-19: Health Prevention and Control in Non-Healthcare Settings. Occupational Medicine 2020; 70(2), 82-83.

5. BUTLER MJ e BARRIENTOS RM. The Impact of Nutrition on COVID-19 Susceptibility and Long-Term Consequences. Brain, Behavior, and Immunity, 2020; 18; S0889-1591(20)30537-7.

6. CHANG JS, et al. Fresh Ginger (Zingiber Officinale) Has Anti-Viral Activity against Human Respiratory Syncytial Virus in Human Respiratory Tract Cell Lines. Journal of Ethnopharmacology, 2013; 145 (1): 146-51.

7. CRODA JHR e GARCIA LP. "Resposta imediata da Vigilância em Saúde à epidemia da COVID-19". Epidemiologia e Serviços de Saúde, 2020; 29(1), e2020002.

8. DECARO N, et al. European Surveillance for Pantropic Canine Coronavirus. Journal of Clinical Microbiology, $2013 ; 51$ (1): 83-88.

9. FENG S, et al. Rational Use of Face Masks in the COVID-19 Pandemic. The Lancet Respiratory Medicine, 2020; $8(5): 434-436$.

10. FRENK J e GÓMEZ-DANTÉS O. La globalización y la nueva salud pública. Salud Pública de México, $2007 ; 49$ (2).

11. GARCIA LP e DUARTE E. Intervenções não farmacológicas para o enfrentamento à epidemia da COVID-19 no Brasil. Epidemiologia e Serviços de Saúde, 2020; 29(2), e2020222.

12. GUIMARÃES MB, et al. As práticas integrativas e complementares no campo da saúde: para uma descolonização dos saberes e práticas. Saúde e Sociedade, 2020; 29 (1): e190297. 
13. GUO YR, et al. The origin, transmission and clinical therapies on coronavirus disease 2019 (COVID-19) outbreak - an update on the status. Military Medical Research, 2020; 7 (1): 11;

14. HERNÁNDEZ A, et al. Two Known Therapies Could Be Useful as Adjuvant Therapy in Critical Patients Infected by COVID-19. Revista Espanola De Anestesiologia Y Reanimacion, 2020.

15. HO CS, et al. Mental Health Strategies to Combat the Psychological Impact of COVID-19 Beyond Paranoia and Panic. Annals of the Academy of Medicine, Singapore, 2020; 49 (3): 155-60.

16. HORMATI A, et al. Can COVID-19 Present Unusual GI Symptoms? Journal of Microbiology, Immunology and Infection, 2020, S1684-1182(20)30080-3

17. HUANG C, et al. Clinical Features of Patients Infected with 2019 Novel Coronavirus in Wuhan, China. The Lancet, 2020; 395 (10223): 497-506.

18. JÚNIOR S de A, et al. COVID-19 e a infecção por SARS-CoV-2 em um panorama geral/ COVID-19 and infection by SARS-CoV-2 in an overview". Brazilian Journal of Health Review, 2020a 3 (2) 3508-22.

19. JUNIOR S de A, et al. Biosafety evaluation and characterization of occupational risks in a ready care unit paulista, Brazil. Research, Society and Development, 2020b; 9 (2).

20. KALANTAR-ZADEH K e MOORE LW. Impact of Nutrition and Diet on COVID-19 Infection and Implications for Kidney Health and Kidney Disease Management. Journal of Renal Nutrition: The Official Journal of the Council on Renal Nutrition of the National Kidney Foundation, 2020; 30 (3): 179-81.

21. KAMEL BOULOS MN e GERAGHTY EM. Geographical Tracking and Mapping of Coronavirus Disease COVID19/Severe Acute Respiratory Syndrome Coronavirus 2 (SARS-CoV-2) Epidemic and Associated Events around the World: How 21st Century GIS Technologies Are Supporting the Global Fight against Outbreaks and Epidemics. International Journal of Health Geographics, 2020; 19 (1): 8.

22. LAUER SA, et al. The Incubation Period of Coronavirus Disease 2019 (COVID-19) From Publicly Reported Confirmed Cases: Estimation and Application. Annals of Internal Medicine, 2020.

23. LUO H, et al. Can Chinese Medicine Be Used for Prevention of Corona Virus Disease 2019 (COVID-19)? A Review of Historical Classics, Research Evidence and Current Prevention Programs. Chinese Journal of Integrative Medicine, 2020; 26 (4): 243-50.

24. MA QX, et al. Potential Utilities of Mask-Wearing and Instant Hand Hygiene for Fighting SARS-CoV-2. Journal of Medical Virology, 2020.

25. MARANHÃO RA e SENHORAS EM. Pacote econômico governamental e o papel do BNDES na guerra contra o novo coronavírus. Boletim de Conjuntura (BOCA,) 2020; 2 (4): 27-39.

26. MARTINS V. Educação, ciência e tecnologia: como desenvolver o Brasil sem investimento? Revista Thema, $2019 ; 16$ (1): $1-3$.

27. OPAS/Brasil Organização Pan-americana da Saúde. Disponível em: https://www.paho.org/bra/index.php?option=com_content\&view=article\&id=6101:covid19\&ltemid=875, Acesso em: 06 de julho de 2020.

28. PARMET WE e SINHA MS. Covid-19 - The Law and Limits of Quarantine". The New England Journal of Medicine, 2020; $382(15)$.

29. RAHIMI F e ABADI ATB. Challenges of Managing the Asymptomatic Carriers of SARS-CoV-2. Travel Medicine and Infectious Disease, 2020, 18:e101677

30. REWAR S, et al. Treatment and Prevention of Pandemic H1N1 Influenza. Annals of Global Health, 2015 ; 81 (5): 64553.

31. ROTHAN HÁ e BYRAREDDY SN. The Epidemiology and Pathogenesis of Coronavirus Disease (COVID-19) Outbreak. Journal of Autoimmunity, 2020; 109.

32. RUELA LO, et al. "Effectiveness of auricular acupuncture in the treatment of cancer pain: randomized clinical trial". Revista da Escola de Enfermagem da USP, 2018.

33. SILVA JB e MUNIZ AMV. Pandemia do Coronavírus no Brasil: Impactos no Território Cearense. Espaço e Economia. Revista brasileira de geografia econômica, 2020 (17).

34. SOHRABI C, et al. Corrigendum to World Health Organization Declares Global Emergency: A Review of the 2019 Novel Coronavirus (COVID-19). International Journal of Surgery (London, England), 2020; 76, 71-76.

35. TANG N, et al. Anticoagulant Treatment Is Associated with Decreased Mortality in Severe Coronavirus Disease 2019 Patients with Coagulopathy. Journal of Thrombosis and Haemostasis, 2020; 18 (5): 1094-99.

36. TANNER WD, et al. Gundlapalli. The Pandemic Potential of Avian Influenza A(H7N9) Virus: A Review. Epidemiology and Infection 2015; 143 (16): 3359-74.

37. VENTURA D. Pandemias e Estado de Exceção, 2009; 22.

38. WOLLHEIM C, et al. Efeito microbicida do ozônio gasoso em Pseudomonas aeruginosa, Staphylococcus aureus e Candida albicans. Revista Ibero-americana de Podologia, 2020; 2 (1): 121.

39. WU Z e McGOOGAN JM. Characteristics of and Important Lessons From the Coronavirus Disease 2019 (COVID-19) Outbreak in China: Summary of a Report of 72314 Cases From the Chinese Center for Disease Control and Prevention. JAMA, 2020; 323 (13): 1239-42.

40. XYDAKIS MS, et al. Smell and Taste Dysfunction in Patients with COVID-19. The Lancet. Infectious Diseases, 2020. 